\title{
26473 - PREOPERATIVE LOW-DOSE KETAMINE REDUCES POSTOPERATIVE PAIN INTENSITY AND TOTAL ANALGESIC CONUMPTION AFTER UROLOGICALICAL SURGERY IN CHILDREN IN AHARY HOSPITAL
}

\section{Shahriar Arbabi Assistant Professor Of Anesthesia, Zahid Hussain K, Anesthesiolgy Professor; Alireza Ebrahim Soltani, Assistant Professor Of Anesthesia; Reza Hamidi , Tehran University Of Medical Sciences, Tehran, TEHRAN, Iran}

Introduction: The objective of this study was to determine whether preoperative low-dose ketamine reduces postoperative pain and analgesic consumption in children undergoing urological surgery.

Methods: 60 children scheduled for urological surgery were included in this prospective study. Anesthesia was performed with fentanyl and Isoflurane. 30 patients additionally received an intravenous bolus of ketamine $(0.3 \mathrm{mg} / \mathrm{kg})$ 3 min before anesthesia induction (Ketamine Group). Another 30 patients received a bolus infusion of saline (Control group). After transfer to the PACU, pain intensity was evaluated using a numeric rating scale (NRS). First patient analgesia request, cumulative analgesic consumption and pain intensities within the first $48 \mathrm{~h}$ were recorded and compared.

Results: Analgesic consumption was significantly different during the first $20 \mathrm{~h}$ (Control: $1.2 \mathrm{mg} / \mathrm{kg}$ ), Ketamine:0.56 mg/kg). Differences were found in pain intensity during the first 26 hours postoperative hour (Control: 4.0, Ketamine: 2.5, $\mathrm{P}<0.05$ ) and in the time to first analgesic request (Control: 37, 28-46 min, Ketamine: 126, 78-141 min; $\mathrm{P}<$ $0.05)$.

DISCUSSION: : preoperative low-dose ketamine reduces pain intensity and analgesic consumption during the first $20 \mathrm{~h}$ after surgery.

\section{REFERENCES:}

1-Fu ES, Miguel R, Scharf JE. Preemptive ketamine decreases postoperative narcotic requirements in patients undergoing abdominal surgery. Anesth Analg 1997; 84: 1086-1090.

2-Dix P, Martindale S, Stoddart PA. Double-blind randomized placebo-controlled trial of the effect of ketamine on postoperative morphine consumption in children following appendicectomy.Paediatr Anaesth 2003; 13: 422-426. 